\title{
Industry Competition, Stability of Contracts and Audit Quality Zhu pu-yi ${ }^{1, a}$
}

${ }^{1}$ Accounting research and development center, Chongqing University of Technology, banan

\author{
district, Chongqing, China \\ roybovey@126.com
}

Keywords: Industry competition, Long-term contracts, Operation states, Audit quality.

\begin{abstract}
Usually, industry competition helps to improve audit quality, but on what types of competition in the industry enterprise audit quality promotion is unclear. This paper attempts to analyze the enterprises according to the state of operation, so as to analyze how the industry competition affects the stability of the contract of different types of enterprises, thus affecting the audit quality. This paper argues that the competition of the industry will result in a stable contractual relationship between the well-run enterprises and large-scale audit firms, while the firms with poor performance are more likely to form stable contractual relationships with smaller audit firms.
\end{abstract}

\section{行业竞争、契约稳定性与审计质量}

\author{
朱谱熠 $1, \mathrm{a}$ \\ ${ }^{1}$ 重庆理工大学财会研究与开发中心, 巴南区, 重庆, 中国 \\ roybovey@126.com
}

关键词：行业竞争 长期契约 经营状态 审计质量

摘要: 一般认为行业竞争有助于审计质量的提升，但是行业竞争对何种类型的企业审计质量 有提升尚不明朗。本文试图对企业按照经营状态进行分析，从而分析行业竞争如何影响不同 类型企业契约的稳定性, 进而影响审计质量。本文认为行业竞争最后会使得经营好的企业与 规模大的事务所形成稳定的契约关系, 而经营差的企业与规模小的事务所更容易形成稳定的 契约关系。

\section{1. 引言}

截止 2016 年 10 月，我国在沪深两市上市的公司共有 2900 家，而这些上市公司年度审 计报告的质量被广为关注。银广夏和南田股份的财务造假使得国内对上市公司的财务审计工 作质量充满担忧, 美国安然公司的财务造假使得大型事务所的审计质量也备受怀疑。虽然审 计市场的供给随着行业的发展在增加, 审计供给的增加一定程度上提升了审计质量, 但是作 为发展中国家的中国也在饱受审计制度不健全对审计质量干扰的痛苦。 


\section{2 . 研究回顾}

\section{1 规模-质量正相关关系及修正}

早期对审计质量的研究多侧重于事务所的规模, 一般认为事务所的规模与审计质量具有 正相关关系。DeAngelo（1981）从声誉和专用性资产两个视角分析了事务所的规模与审计质 量具有正相关关系。规模越大的事务所, 具有更好的声誉, 同时会进行更过的不可转移的专 用型投资。好的审计质量可以维护事务所已获得的声誉, 同时保证专用资产不会受损, 但是 差的审计质量会损害事务所的声誉, 导致巨大的专用资产的损失。因此从维护声誉和专用资 产的角度出发，大事务所相比小事务所更具有提供高质量审计报告的可能性。Watts 和

Zimmerman（1981）的研究也表明这种正相关关系的存在, 但是他们的结论却是规模越大的 事务所有更多的资源监督合伙人的行为，从而提升审计质量。此外，由于事务所的规模大， 所获得的业务多, 因此更容易积累专业技能。该结论在大量的研究被使用, 许多国内学者直 接把事务所规模等同于事务所审计能力。

但是后续的研究对规模与质量的正相关关系进行了修正。对这种正相关影响最大的因素 是政府。一方面政府为本土小规模的事务所和上市公司之间提供建立关系的通道, 另一方面 国有上市公司可以通过政府对事务所施压从而提供超出实际的正的盈余报告。这些都扭曲了 事务所规模与审计质量之间的正向关系 (龚启辉, 2011)。此外, 不健全的法规使得上市企 业追求的不是最高质量的审计报告, 而是符合法规需求的审计报告, 这使得具有高审计水平 的大事务所不具有更强的竞争力（Wang,2008）。

\section{2 高度竞争与高审计质量需求的非必然性}

竞争性市场通常通过竞争促使产品质量的提升, 从而使得高质量的产品提供者获得更多 的市场, 但是对我国审计市场的研究却表明上述结论不完全成立。由于我国早期的事务所多 是脱胎于政府行政部门或由国企改制而成，因此该类事务所与国企具有天然的联系，市场竞 争所带来的高质量审计服务与该类型事务所关系不大，只要它能提供经受政府审查的审计报 告，而该类型的事务所与政府部门也建立良好的关系。因此我国首批事务所的出身对市场竞 争本身是一种破坏（王兵等，2011）。地区间竞争研究同样表明，事务所的地区间竞争优势 越大, 即该所在该地区的业务量比重越大, 那么它能提供的审计服务的质量越高（原红旗, 2012 ）。而这种地区间竞争优势与审计质量的正向关系从另一个方面说明市场垄断越发达, 审计质量越好。

\section{3 契约稳定性与审计质量的双重关系}

契约稳定性与审计质量的关系一般从两个维度分析。一般认为，长期的审计契约可以让 事务所与客户建立长期关系, 可以提升审计师的专业能力, 进而提升审计质量 （Mautz,1961）。同时, 随着长期交往, 审计师能够获得客户的专门知识, 对审计对象的了 解更加全面, 从而可以获得更高的审计质量 (Myers,2003)。但是, 这种长期关系的建立也 在危害着审计质量的提升。存在异常聘任关系时, 审计师由于与客户的长期契约从而结成了 亲密的私人关系, 这种私人关系会破坏审计师审计的独立性, 从而使得审计质量下降 (刘启 亮，2009）。审计师对行业过度熟悉会降低审计师的独立性，同时固化设计师的设计方法和 程序, 从而降低审计质量（池玉莲，2015）。许浩然（2016）用分析师跟踪作为代理变量分 析审计质量与审计任期时, 同样得出两者呈现负相关, 这也意味着稳定的契约关系与审计质 量存在相反的关系。因此, 稳定的契约一方面强化审计师的专业技能, 从而提升审计质量, 但是另一方面会使得审计师与客户形成更亲密的私人关系, 从而影响给出真实审计报告的意 愿，降低审计质量。 
虽然大量学者对从不同视角行业竞争以及契约的长短如何影响审计质量进行了研究，但 是目前还没有学者研究这两个影响因素如何相互作用。本文试图分析行业竞争对契约长短会 产生何种影响，进而对审计质量有何影响。

\section{3 . 模型分析}

审计质量受两个因素影响: 审计师专长和审计师独立性。审计师专长影响审计工作中获 得企业真实财务信息的能力, 审计师独立性影响审计报告与审计师所获得的信息之间的差异。 审计师的业务能力越强, 审计师受到其他因素影响越少, 所提供的审计报告与自身获知的审 计信息越一致，其提供的审计报告质量越高。本文也以审计师专长和审计师独立性两个指标 来描述审计质量。

\section{1 问题描述}

假定区域内存在一定数量的事务所提供审计活动，这些事务所与当地政府存在一定程度 的关联，外来的事务所规模更大。同时假定事务所规模与专业能力正相关。企业进行审计服 务需求的目的是向外界提供财务审计信息，但是所提供的信息要尽量不会诱导相关利益者对 企业的后续经营造成损害。因此本文把企业分为两类：一类是经营良好的企业，该类企业即 使提供了真实的审计报告, 其报告内容对企业经营也不会造成损害; 另一类企业是经营不善 的企业，如果提供的审计报告真实而不加修饰，那么该报告会对企业经营造成不良影响。

\section{假定:}

$\mathrm{Q}$ ：审计质量。该审计质量由事务所的技术专长和审计师的独立性共同决定，即 $Q=Q_{\mathrm{s}}-Q_{i}, Q_{\mathrm{s}}$ 为技术专长所决定的审计质量, $Q_{\mathrm{i}}$ 为审计师独立性不足从而导致不能真实 地反应所获得信息对审计质量的影响。

$f_{L}$ : 为当地小规模技术专长不足的事务所;

$f_{H}$ : 为外来的大规模技术专长占优的事务所。

\section{2 基本模型}

根据上述问题描述，可以获得基本模型

$$
Q=Q_{s}\left(f_{L}, f_{H}\right)-Q_{i}\left(f_{L}, f_{H}\right)
$$

由于此处假定外来的事务所具有更强的技术专长但是不具有与政府及当地企业的人脉关 系, 因此可以假定在外来事务所 $f_{H}$ 对 $Q_{\mathrm{s}}$ 的影响比本地事务所 $f_{L}$ 对 $Q_{\mathrm{s}}$ 的影响大, 但是对 $Q_{\mathrm{i}}$ 的影响比本地事务所小。由此式 (1) 的详细表达式可改写成:

$$
\begin{aligned}
& Q_{H}=a E_{H}-c I_{H} \\
& Q_{L}=b E_{L}-d I_{L}
\end{aligned}
$$

式 (2) 为外来竞争者在 $\mathrm{E}$ 单位的努力下所提供的审计质量, $a$ 为外地事务所的技术专 长质量系数, $\mathrm{c}$ 为外地事务所的关系质量系数。式 (3) 为本地事务所在 $\mathrm{E}$ 单位努力下所提 供的审计质量, $\mathrm{b}$ 是本地事务所的技术专长质量系数, $\mathrm{d}$ 为本地事务所的关系质量系数。假 如不考虑外来者和本地者努力的边际成本差异，那么根据上述分析可知， $a>b, c<d$, $Q_{H}>Q_{L}$ 。因此, 在追求审计质量的背景下, 本地事务所将不具备任何竞争优势, 业务将被 外来的大事务所获得。王咏梅（2006）在对中国市场上国际著名的四家事务所与非四大事务 所的审计质量市场认同度的研究同样表明, 四大的审计质量具有明显的高认同度。因此规模 大或者说高度专长的事务所被接受的可能性更大。

考虑到审计的财务结果公开后会对企业的经营造成影响, 故此假定存在一个中性的财务 结果 $\bar{Q}$, 如果企业公布的审计结果为 $\bar{Q}$, 则外界对企业的审计结果无反应, 不会对企业的 后续经营产生影响。如果审计报告优于 $\bar{Q}$, 则外界对企业的后续经营产生好的影响, 反之 
则产生坏的影响。因此可以把企业分成两类：一类为经营好的企业, 自身实际的财务信息优 于 $\bar{Q}$, 记作 $F_{H}$; 一类是实际的财务信息劣于 $\bar{Q}$, 记作 $F_{L}$ 。那么 $F_{H}$ 类企业会追求更好的审 计报告, 至少要反映企业真实的财务信息, $F_{L}$ 类型的企业会追求尽可能好的审计报告, 但 是这种需求是以审计报告偏离真实财务信息为前提，偏离的越多越好。

假如企业选择 $f_{L}$ 类型的事务所, 那么 $f_{L}$ 事务所不太专长的专业技能使得事务所获得的 信息与企业真实的财务信息存在一个较大的误差, 用 $\Delta Q_{L}$ 表示, $\Delta Q_{L}=\varepsilon(1-b) \bar{Q}_{L}$, 此处表 明事务所技术越专不长, $\mathrm{b}$ 越小，事务所获得的信息误差就越大。即使考虑到本地事务所与 企业存在良好的关系从而使得审计报告的财务信息改善，但是审计违规存在巨大的法律成本， 因此这种改善程度存在一个界限, 可以用一个很小的波动来描述, 则 $\Delta Q_{L}=\varepsilon(1-b+d) \bar{Q}_{L}$, 即关系会扩大事务所审计报告的信息与企业真实财务信息的误差, 关系越好, 报告提交的信 息与真实信息的误差就可以越大。如果选定的是一个 $f_{H}$ 类型事务所, 则

$$
\Delta Q_{H}=\varepsilon(1-a+c) \bar{Q}_{H}, \Delta Q_{L}>\Delta Q_{H} \text { 。 }
$$

作为 $F_{H}$ 型企业, 由于本身真实的财务信息能够保证企业所披露的信息不损害企业后续 的经营, 该类型企业没有太大的激励提供低质量的、虚假的审计报告。假如选择 $f_{L}$ 型事务 所，其获得的审计报告与真实的财务信息差距较大，将会产生较大的信息误差

$\Delta Q_{L}=\varepsilon(1-b+d) \bar{Q}_{L}$ 。如果选择 $f_{H}$ 型事务所, 则只会产生较小的信息误差 $\Delta Q_{H}=\varepsilon(1-a+c) \bar{Q}_{H}$ 。因此从收益角度衡量, 好的企业会选择规模大的外来的事务所, 进 而提供较少信息误差的审计报告。因为提供的审计报告信息误差越少, 其审计结果越靠近真 实财务信息远离中性财务结果, 对企业有益。如果选择 $f_{L}$, 则审计报告的误差越大, 审计 结果越远离真实财务信息。因此经营好的企业更容易与规模大的事务所建立长期契约。

作为作为 $F_{L}$ 型企业，由于本身真实的财务信息使得企业所披露的信息损害企业后续的 经营，该类型企业有提供低质量的、虚假的审计报告的动机。假如选择 $f_{L}$ 型事务所，其获 得的审计报告与真实的财务信息差距较大, 将会产生较大的信息误差 $\Delta Q_{L}=\varepsilon(1-b+d) \bar{Q}_{L}$ 。 如果选择 $f_{H}$ 型事务所, 则只会产生较小的信息误差 $\Delta Q_{H}=\varepsilon(1-a+c) \bar{Q}_{H}$ 。因此从收益角 度衡量, 经营差的企业会选择本地事务所, 进而提供较多信息误差的审计报告。因为提供的 审计报告信息 误差越多，其审计结果越靠近真实财务信息远离中性财务结果，对 $F_{L}$ 型企业 有益。如果选择 $f_{H}$ 型事务所, 事务所处于安全考虑, 会提供较少误差但是较差财务结果的 审计报告, 这对经营差的企业产生不好的影响。因此经营差的企业即使第一次选择规模大专 业性强的事务所, 事后也会因为不满意真实的审计报告而变更合作伙伴, 很难与规模大的事 务所建立长期契约，从而更容易与 $f_{L}$ 型事务所建立长期契约。

\section{3 一个扩展模型}

当外来的、规模大的事务所进入该市场的时间较长后, 会与当地政府及企业建立较好的 联系, 同时会与长期客户建立良好的私人联系, 从而使得审计师的独立性变差。与此同时, 本地事务所会因为外来事务所的压力而提升自身的专长。因此, 式 (2) 和式 (3) 将变成式 (4) 和式 (5)。

$$
\begin{gathered}
Q_{H}=(a+\Delta a) E_{H}-(c+\Delta \mathrm{c}) I_{H} \\
Q_{L}=(b+\Delta b) E_{L}-d I_{L}
\end{gathered}
$$

式 (4) 中 $\Delta a$ 是因为外来事务所因为与本地企业长期的契约关系从而获得本地企业相关 业务技巧，从而提升自身获得企业真实信息的能力，进而可以提供更高质量的审计报告。 $\Delta \mathrm{c}$ 表示因为与本地企业长期的契约关系, 由此形成的密切的私人关系使得审计师的独立性 
变差, 从而提供的审计报告的真实性变差。式 (5) 中的 $\Delta b$ 是本地事务所因为外地事务所的 进入而被迫提升自身的技术专长带来的审计质量提升的幅度。由于本地事务所长期与本地企 业交往, 因此长期契约对其审计独立性的影响不大。由此, 从长期来看, 由于本地事务所的 被迫学习提升了专长, 使得本地与外地事务所的技能差距在缩小。同时, 由于外地事务所在 长期契约的影响下, 其原本较高的独立性在变差, 与本地事务所较差的独立性趋同。外来、 规模大的事务所的审计质量有下降的危险，而本地事务所在竞争中审计质量会提升。

通过行业竞争和长期契约的关系建立，本地事务所在努力缩小与大事务所的专长差距， 而大事务所也被迫因为长期契约建立的私人关系逐步丧失自身的独立性。但是经营好的 $F_{H}$ 类型企业由于自身追求审计报告的真实性和公众可信度, 因此会更愿意选择具有更好声誉的 $f_{H}$ 型事务所。同时初期 $F_{H}$ 类型企业对 $f_{H}$ 型事务所的偏好会使的 $F_{H}$ 类型企业更愿意与 $f_{H}$ 型事务所签订长期契约, 从而在获得更真实和公众接受度高的审计服务的同时节约交易成本。 而 $F_{L}$ 由于追求的是财务表现更好的审计报告, 因此从长期来看, 只有本地小规模的事务所 愿意承担更大风险出具与真实财务信息偏差更大的审计报告。同时, 在 $f_{H}$ 型事务所进入本 地市场的初期, $F_{L}$ 型企业就很难跟 $f_{H}$ 型事务建立长期契约, 但是容易跟 $f_{L}$ 型事务所建立长 期契约。长期契约的建立有利于节约交易成本, 因此从长期来看 $F_{L}$ 型企业与 $f_{L}$ 型事务更容 易建立长期契约。

尤克清和卜华 (2016) 在对 2011 年到 2013 年间沪深两市的相关上市公司的实证研究结 果同样显示, 盈余管理程度强的企业偏好低质量的事务所, 这与本文结论中经营不善的企业 偏好低质量事务所有相同之处，经营不善的企业有更强的盈余管理需求。

\section{4. 结论}

行业竞争会使得有差异的事务所在技术专长和设计师独立性方面有趋同现象, 但是规模 大的事务所进入某一地区的初期更容易被经营好的企业所接受, 从而容易形成经营好的企业 与规模大的事务所结成长期契约, 这种长期契约的形成有助于外来事务所改善与当地企业的 私人关系, 但是会丧失一定的审计的独立性。而规模小的本土企业相对更容易被经营差的企 业所接受，从而形成长期契约，但是长期竞争有助于本地事务所提升审计质量。

\section{References}

[1] Gong Qihui. Dual effect of government control on audit quality, Accounting Research, vol.8, pp. 68-76, 2011.

[2] Yuan Hongqi, Han Weifang. CPA firm's regional competitive advantage and audit quality, Accounting Research, vol.2, pp. 67-74, 2012.

[3] Wang Yongmei, Wang Peng. Research on the difference in market reactions to auditor's financial statements between big-fours and non-big-fours, Auditing Research, vol. 5, pp. 49-56, 2006.

[4] Wang Bing, Li Jing. Cana dministrative punishment improve the audit quality?- the punishment evidence from the China Securities Regulatory Commission, Accounting Research, vol.12, pp. 34-42, 2011.

[5] Liu Qiliang, Tang Jianxin. Study effect, private relationship, audit tenure and audit quality, Auditing Research, vol. 4, pp. 52-64, 2009.

[6] Chi Yulian, Yang Ningxia. Auditor tenure, firm tenure and audit quality, The Chinese Certified Public Accountant, vol. 1, pp. 85-90, 2015

[7] You Keqing, Bo Hua. Research on auditor-customer distance and audit quality, The Chinese Certified Public Accountant, vol. 3, pp. 74-79, 2016. 
[8] $\mathrm{Xu}$ Haorang, Zhang Wen. Analyst tracking, auditing tenure and audit quality, Modern Management Science, vol. 7, pp. 51-53, 2016

[9] DeAngelo,L. Auditor size and audit quality, Journal of Accounting \& Economics, vol. 3, pp. 183-199,1981.

[10] Wang,Q.State ownership, the institutional environment, and auditor choice: evidence from china, Journal of accounting and economics, vol. 46, pp. 112-134, 2008. 